\title{
Simulação do comportamento mecânico de misturas asfálticas usando um modelo computacional multi-escala
}

\author{
Flávio Vasconcelos de Souza \\ Jorge Barbosa Soares \\ Programa de Mestrado em Engenharia de Transportes - PETRAN, Universidade Federal do Ceará, Brasil
}

RESUMO: As misturas asfálticas, por serem materiais heterogêneos, possuem comportamento global dependente do comportamento dos constituintes individuais, de suas frações volumétricas e das interações físico-químicas entre os constituintes, dentre outros fatores. Deste modo, para que se possa compreender melhor o comportamento desses materiais, é necessário o uso de metodologias capazes de considerar as características e fenômenos ocorrentes nas escalas menores. Uma metodologia que vem sendo bastante estudada e aplicada na comunidade científica internacional são os chamados modelos multi-escala. O objetivo do presente trabalho é descrever um modelo computacional multi-escala e aplicá-lo à simulação de ensaios comumente usados em misturas asfálticas, quais sejam, os ensaios de compressão diametral e de fadiga por flexão em viga. Para o caso de compressão diametral, os resultados numéricos se mostraram em concordância com os resultados observados experimentalmente. Para o caso de carregamento cíclico, não foi feita uma comparação com experimentos, mas os resultados numéricos mostram a capacidade do modelo em simular qualitativamente os fenômenos de trincamento por fadiga e acúmulo de deformações permanentes.

\begin{abstract}
Given that asphalt mixtures are composite materials, their behavior is fundamentally determined by the local behavior of their constituents, their volume fraction and their physical-chemical interactions. Thus, in order to better understand the mechanical response of asphalt mixtures, it is necessary the use of methodologies that accurately consider the characteristics and phenomena that occur in smaller scales. A methodology that has been very studied and applied by the international scientific community is the so-called multi-scale modeling. The aim of the present paper is to describe and apply a computational multi-scale model to the numerical simulation of commonly used tests, such as the indirect tension test (Brazilian test) and the fatigue beam test. From the simulations of the indirect tension test, it was observed that the numerical results are in agreement with the experimental ones. In the case of cyclic loading, no experiments were performed, but the numerical results show that the model may qualitatively simulate both fatigue cracking and accumulation of permanent deformations.
\end{abstract}

\section{INTRODUÇÃO}

O uso de materiais compósitos, ou seja, materiais formados a partir da combinação de dois ou mais constituintes individuais, em aplicações estruturais tem crescido de forma significativa nos últimos anos, destacando-se as aplicações nos diversos ramos das engenharias aeroespacial, biomédica, civil e mecânica. Esse uso crescente deve-se ao fato de que os materiais compósitos podem oferecer características estruturais ótimas para determinadas aplicações que seus constituintes não podem oferecer individualmente.

Além disso, observa-se uma preocupação crescente em se minimizar o passivo ambiental provocado por certos materiais aparentemente inservíveis, os quais podem ser aproveitados como constituintes dos materiais asfálticos, como é o caso do asfalto-borracha e do aproveitamento de resíduo da construção civil (entulho) na fabricação de misturas asfálticas. Por outro lado, o acréscimo desse material inservível não deve piorar as características do novo material a ponto de ele não poder ser aplicado em campo. Assim sendo, é preciso que se determinem quais os tipos de materiais inservíveis e suas frações volumétricas que podem ser incorporados de modo a não acarretar perdas no desempenho do novo material.

As misturas asfálticas, produzidas a partir da combinação do ligante asfáltico com outros materiais, como a brita, a areia ou a borracha, são consideradas materiais compósitos e constituem um material com características diferentes dos seus constituintes individuais. As propriedades globais dos materiais compósitos dependem das propriedades dos seus constituintes individuais, das suas frações volumétricas e do modo como seus constituintes interagem física e quimicamente, dentre outros fatores. 
Desta forma, para se otimizar o desempenho das misturas asfálticas e desenvolver novos materiais a partir dos constituintes individuais disponíveis, é necessário o uso de metodologias capazes de reter o máximo de informações sobre a microestrutura do compósito a fim de determinar as frações e distribuições ótimas desses constituintes para cada tipo de aplicação. Uma metodologia que vem sendo bastante usada na comunidade científica na análise de materiais compósitos é a chamada modelagem multi-escala (Yi et al., 1998; Caiazzo e Costanzo, 2001; Haj-Ali e Muliana, 2004; Searcy, 2004; Souza, 2005).

Dentre as principais causas da deterioração precoce dos pavimentos asfálticos, destacam-se o acúmulo excessivo de deformação permanente e o trincamento por fadiga. Estes fenômenos estão relacionados a fenômenos inerentes às escalas menores. O trincamento está relacionado aos fenômenos de micro-fissuração na mistura asfáltica e concentração de tensões nas interfaces agregados-ligante, enquanto o desenvolvimento de deformações permanentes está associado à dissipação de energia provocada pelo comportamento viscoelástico do ligante e acúmulo de microtrincas. Assim sendo, se por um lado, a redução da fração volumétrica de ligante asfáltico na mistura reduz a susceptibilidade a deformações permanentes, o aumento na fração volumétrica de agregados pétreos aumenta a susceptibilidade ao trincamento.

O método de projeto de misturas asfálticas atualmente mais utilizado no Brasil, o método Marshall (DNER, 1995), não considera o real comportamento dos materiais asfálticos, os quais apresentam comportamento viscoelástico (Pinto, 1991; Goodrich, 1991; SHRP, 1994a; LCPC, 1997; Daniel e Kim, 2002; Souza e Soares, 2003a; 2003b; Souza et al., 2005), nem os fenômenos que ocorrem nas escalas menores da mistura. Isso, portanto, dificulta um projeto mais confiável das misturas asfálticas e, conseqüentemente, dos pavimentos asfálticos.

A metodologia Superpave, já bastante utilizada nos países desenvolvidos, avançou de forma considerável no que tange à caracterização e classificação dos materiais de pavimentação, especialmente no que diz respeito aos ligantes asfálticos. Neste sentido, muitos conceitos importantes da reologia dos ligantes, a qual está intimamente ligada à Teoria da Viscoelasticidade, foram incorporados, como a utilização dos parâmetros $\mathrm{G}^{*}$ (módulo complexo de cisalhamento) e $\delta$ (ângulo de fase), determinados pelo ensaio de cisalhamento dinâmico (DSR Dynamic Shear Rheometer), e a utilização de uma faixa de temperatura para a qual esses parâmetros devem ser avaliados (SHRP, 1994b, 1994c; Motta et al., 1996).
Entretanto, no que diz respeito ao projeto de misturas asfálticas, a metodologia Superpave ainda não é capaz de considerar explicitamente fatores característicos das escalas menores e que determinam o comportamento global da mistura, como as interações entre o ligante e os agregados, fração volumétrica ótima dos constituintes, dentre outros.

Por outro lado, a consideração dos fenômenos ocorrentes nas escalas menores através de alguma metodologia, como os modelos multi-escala, proporciona uma previsão mais confiável do comportamento global da mistura asfáltica em serviço, além de possibilitar ao projetista uma sensibilidade maior com relação à influência de determinadas características da mistura no comportamento global da mesma.

O objetivo do presente trabalho é mostrar a capacidade de um modelo computacional multi-escala em simular o comportamento de misturas asfálticas sob as condições de carregamento do ensaio de compressão diametral, considerando-se os fenômenos ocorrentes na escala menor (heterogeneidade, viscoelasticidade do ligante, microtrincamento e concentração de tensões nas interfaces ligante-agregados). Por limitação computacional, consideram-se apenas duas escalas. São simuladas duas situações de carregamento: monotônico e cíclico. No caso do carregamento monotônico, os resultados numéricos são comparados com os obtidos experimentalmente a partir do ensaio de compressão diametral. No caso do carregamento cíclico, não são realizados experimentos, mas simula-se o ensaio de fadiga por flexão em viga bi-apoiada com o objetivo de mostrar a capacidade do modelo computacional multi-escala em simular os principais fatores de deterioração dos pavimentos asfálticos nacionais, quais sejam, o trincamento por fadiga e o acúmulo de deformações permanentes.

\section{REVISÃO BIBLIOGRÁFICA}

O modelo computacional multi-escala para análise estrutural de misturas asfálticas apresentado em Souza (2005) se baseia fundamentalmente em quatro teorias, quais sejam: $i$ ) o Método dos Elementos Finitos (MEF), método numérico usado para implementação do modelo computacional; ii) a Teoria da Viscoelasticidade, modelo constitutivo usado para descrever o comportamento dos materiais asfálticos; iii) a Mecânica da Fratura, sendo o modelo de zona coesiva micromecânico viscoelástico (MZC-MV), desenvolvido por Allen e Searcy (2001), o modelo usado para simular a formação e propagação de trincas nos materiais asfálticos; e $i v$ ) as Teorias de Homogeneização, sendo os modelos multi-escala a teoria de homogeneização abordada. Visto que 
os modelos multi-escala são o foco principal deste trabalho, eles são brevemente revisados a seguir. Maiores detalhes sobre eles e demais teorias, além de algumas de suas principais referências podem ser encontrados em Souza (2005).

\subsection{Modelos Multi-Escala}

As Teorias de Homogeneização podem ser definidas como uma classe de modelos constitutivos cujo objetivo principal é prever o comportamento global de materiais heterogêneos com base no arranjo geométrico e no comportamento dos seus materiais constituintes (Searcy, 2004). Esse comportamento global é encontrado através da solução de um problema micromecânico e posterior obtenção da média dos campos mecânicos (tensões, deformações e deslocamentos) por meio de técnicas de homogeneização (Allen, 2001). Os problemas micromecânicos são formulados e resolvidos para o Elemento de Volume Representativo (EVR), o qual pode ser definido como o menor volume capaz de representar de forma suficientemente precisa o comportamento global do material.

Mais especificamente, as Teorias de Homogeneização podem ser classificadas conforme a filosofia de previsão do comportamento global do material em $i$ ) teoria de homogeneização clássica e ii) modelos multi-escala. Na teoria de homogeneização clássica, a relação constitutiva global e as propriedades efetivas, ou homogeneizadas, do material são obtidas a priori, a partir de alguma técnica de homogeneização, e usadas nas análises a posteriori das peças estruturais. Nos modelos multi-escala, entretanto, não se procura determinar as propriedades homogeneizadas. Nesses modelos, a análise global (escala macro) é realizada através de métodos comuns, mas sempre que há necessidade de se obter informações com relação ao comportamento constitutivo do material, um problema de valor de contorno micromecânico deve ser resolvido explicitamente (Caiazzo e Costanzo, 2000).

Vale salientar que, embora existam muitas soluções analíticas para o caso de compósitos que apresentam comportamento constitutivo elástico, microestrutura periódica e geometrias internas simples, a busca por soluções fechadas torna-se impraticável quando o compósito apresenta constituintes inelásticos, de formas irregulares, distribuídos e orientados aleatoriamente, e quando se considera a formação e propagação de microtrincas (Searcy, 2004). Nestes casos, portanto, torna-se mais atraente a utilização de métodos numéricos, como o Método dos Elementos Finitos (MEF).

A análise multi-escala pode ser resumida da seguinte forma: para cada ponto geométrico do problema global realiza-se uma análise local, sendo as condições de contorno locais determinadas a partir da solicitação gerada no problema global. $\mathrm{Na}$ análise

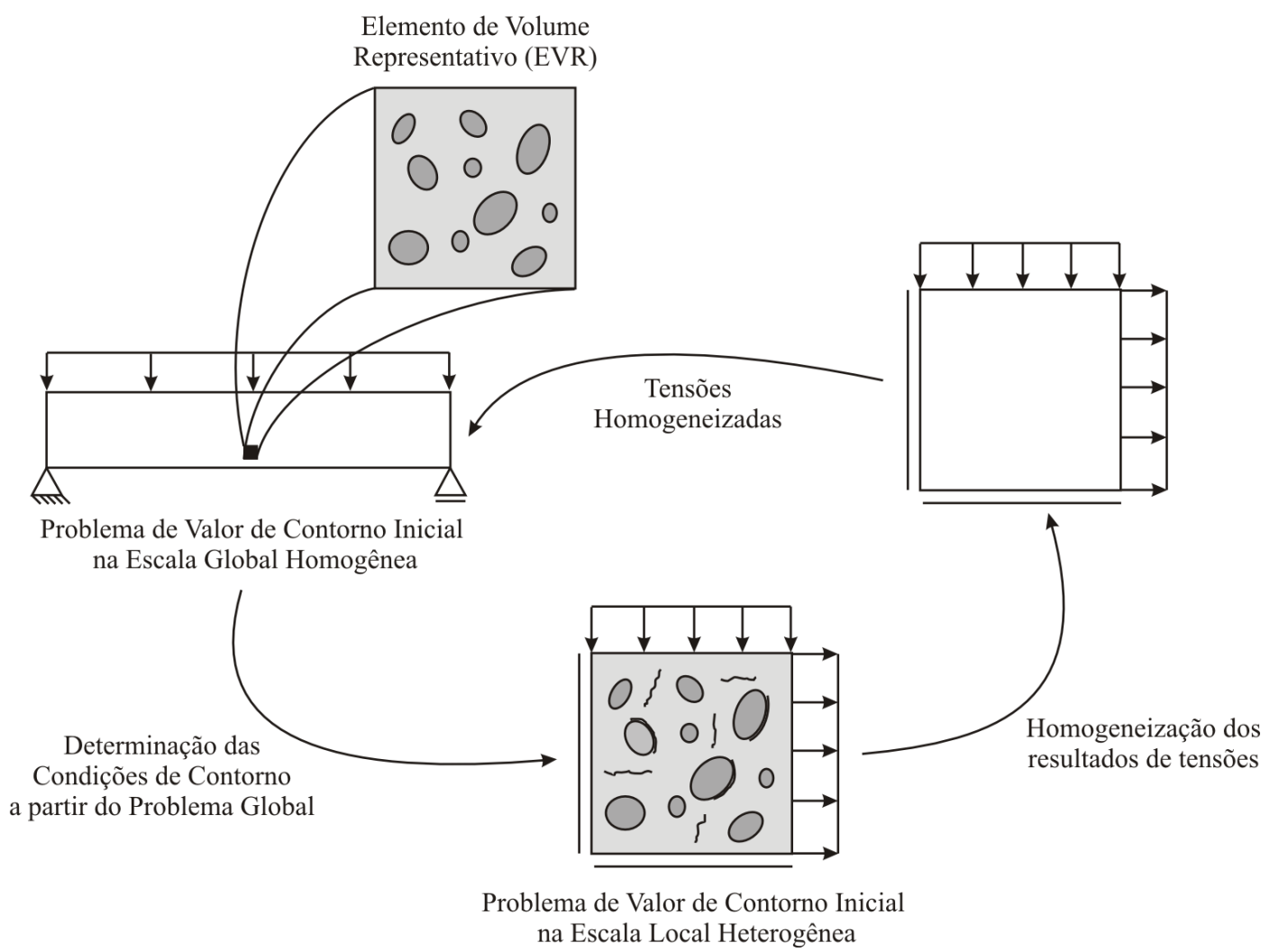

Figura 1: Representação esquemática de uma análise multi-escala 
local pode se considerar a heterogeneidade do material, a formação e propagação de microtrincas e os demais mecanismos de dissipação e ganho de energia. Realizada a análise local, seus resultados de tensão podem ser homogeneizados através de teoremas de média e retornados ao problema global (Allen, 2001). A Figura 1 mostra uma representação esquemática de uma análise em duas escalas. Para o caso de a análise global ser realizada através do MEF, uma análise micromecânica correspondente deve ser realizada para cada ponto de integração pré-selecionado da malha de elementos finitos (Caiazzo e Costanzo, 2000; Feyel e Chaboche, 2000).

A principal vantagem das análises multi-escala e demais modelos baseados na Micromecânica é que os fenômenos físicos contidos na escala menor são visualizados quando da solução do problema micromecânico, podendo-se, portanto, avaliar a influência destes no comportamento global, e prevenindo-se os mecanismos de evolução do dano e a falha precoce do material.

Uma outra vantagem é que, uma vez determinadas as propriedades constitutivas dos materiais constituintes, a propriedade efetiva (ou homogeneizada) do compósito resultante pode ser determinada computacionalmente para qualquer fração e/ou distribuição dos constituintes individuais sem a necessidade de realização de grandes quantidades de ensaios experimentais.

A principal limitação dos modelos multi-escala convencionais e das teorias de homogeneização clássica é que ambos assumem a hipótese simplificadora de que o tamanho da escala local, $\ell_{\text {local }}$, é muito menor que o da escala global, $\ell_{\text {global }}\left(\ell_{\text {local }}<<\ell_{\text {global }}\right)$. A interpretação física dessa hipótese é que a microestrutura local corresponderia apenas a um ponto na escala global. Assumindo-se essa hipótese como verdadeira, não é preciso, portanto, transmitir o gradiente de deformações da escala global para a escala local, visto que tal hipótese implica na uniformidade das deformações globais ao longo do EVR. A principal conseqüência dessa simplificação é que se impossibilita a modelagem do chamado efeito de tamanho (size effect) (Bazant e Planas, 1998) e da localização de deformações (alto gradiente de deformações) na escala global (Kouznetsova, 2002).

É importante ressaltar que embora necessitem de uma grande quantidade de memória computacional, devido à existência de um problema micromecânico para cada ponto de integração, os modelos multiescala proporcionam uma economia de esforço e memória computacional se comparados aos modelos onde o material é considerado um meio totalmente heterogêneo (análise global heterogênea). Além disso, é possível reduzir de forma drástica o tempo computacional consumido pelos códigos multi-escala através da incorporação de técnicas avançadas de solução de sistemas de equações, como a computação paralela.

\section{MATERIAIS E MÉTODOS}

\subsection{Materiais}

O CAP aqui utilizado é o CAP 50/60 fornecido pela Petrobras/Lubnor e oriundo do petróleo Fazenda Alegre. Os agregados usados podem ser classificados como areia de campo, constituindo-se de frações de granulometria média e fina, sendo suas propriedades elásticas assumidas com base no estudo de Mehta e Monteiro (1993). A mistura asfáltica em AAUQ, compactada no compactador giratório Superpave, apresenta um teor de CAP de 9,0\%, determinado pelo método de dosagem Marshall (DNER, 1995), um volume de vazios de 5\% e uma relação betume-vazios de $80 \%$.

O mastique constitui-se da mistura do CAP com a fração mais fina dos agregados que não foi capturada durante o processo de digitalização da seção transversal dos corpos de prova, o qual será descrito na próxima seção. A menor dimensão das partículas capturadas foi de $0,40 \mathrm{~mm}$, de modo que as frações finas a partir da peneira $\mathrm{N}^{\circ} 40$ (abertura de $0,42 \mathrm{~mm}$ ) foram usadas na confecção dos corpos de prova de mastique. Com relação às propriedades constitutivas do mastique, a Figura 2 mostra a função fluência, $D(t)$, determinada experimentalmente, e o módulo de relaxação, $E(t)$, determinado por interconversão (Park e Schapery, 1999; Souza, 2005).

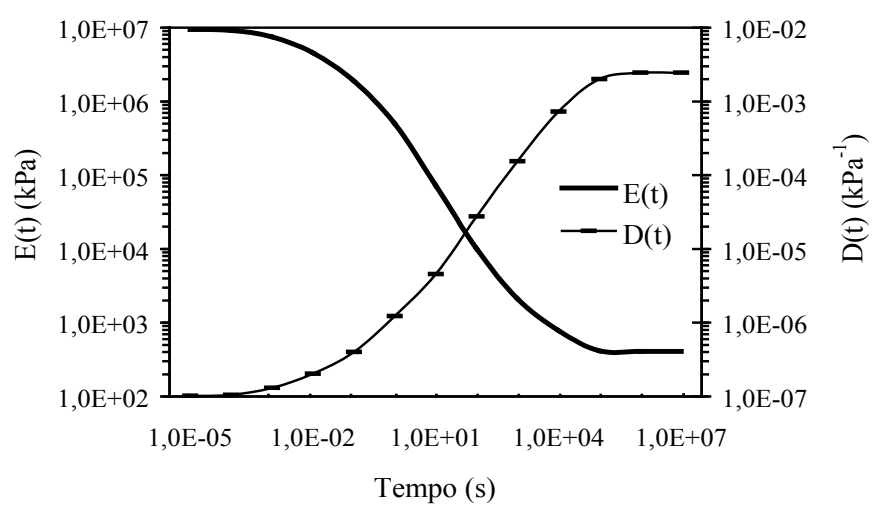

Figura 2: Módulo de relaxação e função fluência do mastique

\subsection{Determinação do EVR}

A estrutura da escala local (escala microscópica) foi determinada a partir de seções transversais de alguns dos corpos de prova serrados diametralmente. Essas seções foram, então, digitalizadas ("escaneadas") 
para permitir a criação do modelo geométrico representativo da escala local a partir da definição dos contornos dos agregados numa região pré-selecionada. A partir dessa região, podem-se definir diversos elementos de volume (EV), dentre os quais um foi definido como o elemento de volume representativo (EVR). Os elementos de volume selecionados correspondem a subdivisões da região pré-selecionada, conforme mostra a Figura 3.

O EVR foi determinado seguindo-se uma metodologia semelhante à usada por Stroeven et al. (2004), onde uma propriedade do material é utilizada como critério de representatividade do elemento de volume. No caso do presente trabalho, a propriedade considerada foi o módulo de relaxação linear do EV. Além deste, o critério geométrico da distribuição estatística do tamanho dos agregados também foi considerado na determinação do EVR (Allen, 2001; Seidel et al., 2004).

Dentre os três Elementos de Volume estudados, o EV-02 foi definido como o Elemento de Volume Representativo (EVR) de acordo com os critérios apresentados e por apresentar uma malha de elementos finitos mais leve que a do EV-03.

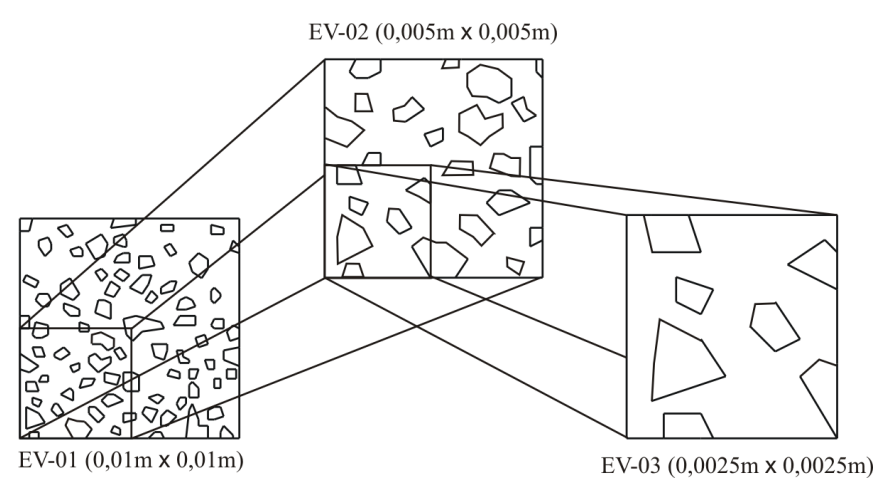

Figura 3: Elementos de volume selecionados

\subsection{Determinação do Módulo de Relaxação da AAUQ}

No presente trabalho, a equação desenvolvida por Allen e Yoon (1998) para o cálculo do módulo de relaxação homogeneizado de materiais compósitos viscoelásticos, foi resolvida numericamente para o EVR determinado, o qual representa a AAUQ. A Figura 4 mostra uma comparação entre os módulos de relaxação da AAUQ e do mastique. Observa-se desta figura que a adição de agregados ao mastique aumenta a rigidez do material de forma não homogênea ao longo da escala de tempo. Isto se deve principalmente às interações entre o mastique e os agregados desenvolvidas durante o processo de relaxação do mastique.

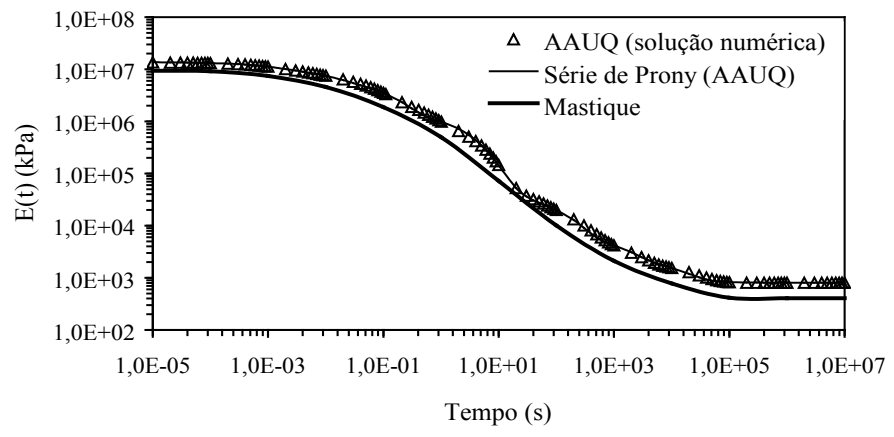

Figura 4: Módulo de relaxação da AAUQ

\subsection{Geração das Malhas de Elementos Finitos}

Para os casos em que não há elementos de interface, as malhas de elementos finitos foram geradas por triangulação, com elementos triangulares de três nós (T3) utilizando-se o programa Mtool (Tecgraf5, 1997), semelhantemente à metodologia usada por Freitas (2002).

No caso da utilização de elementos de interface, as malhas foram inicialmente geradas pelo Mtool, sendo que um novo algoritmo foi desenvolvido para inserir elementos de interface nas interfaces mastique-mastique e mastique-agregado. Este algoritmo primeiramente detecta todas as interfaces entre os elementos T3 e as classifica em interface mastiquemastique, mastique-agregado e agregado-agregado. Em seguida, cria elementos de interface nas interfaces mastique-mastique e mastique-agregado e atualiza a conectividade dos elementos T3. Após a geração da nova malha com elementos de interface, o algoritmo segue para uma rotina onde o algoritmo reverso de Cuthill-McKee (Cuthill e Mckee, 1969), o qual reduz a largura de banda através da reordenação dos nós, foi implementado, de modo que a malha final com elementos de interface proporcione um menor esforço computacional.

A Figura 5 mostra a malha de elementos finitos com elementos de interface (linhas mais espessas) usada para o EVR. Note-se que há elementos de interface entre todos os elementos da matriz viscoelástica (mastique) e nas interfaces mastique-agregados.

Note-se que, objetivando reduzir o esforço computacional, a análise multi-escala é realizada apenas nos elementos mais suscetíveis à evolução do dano. Além disso, procurou-se tirar proveito da simetria dos problemas, modelando-se apenas um quarto do corpo de prova para o caso de compressão diametral e metade do corpo de prova para as simulações em viga, conforme mostra a Figura 6 . Vale ressaltar que, no caso da escala local, foram inseridos elementos de interface em todas as interfaces entre os elementos da matriz viscoelástica (mastique) e nas interfaces entre o mastique e os agregados. Além disso, nas 
simulações em viga, utilizaram-se duas malhas para o problema global, uma sem elementos de interface e outra com elementos de interface dispostos ao longo de toda a malha, mantendo-se em ambos os casos a mesma geometria e número de elementos T3.

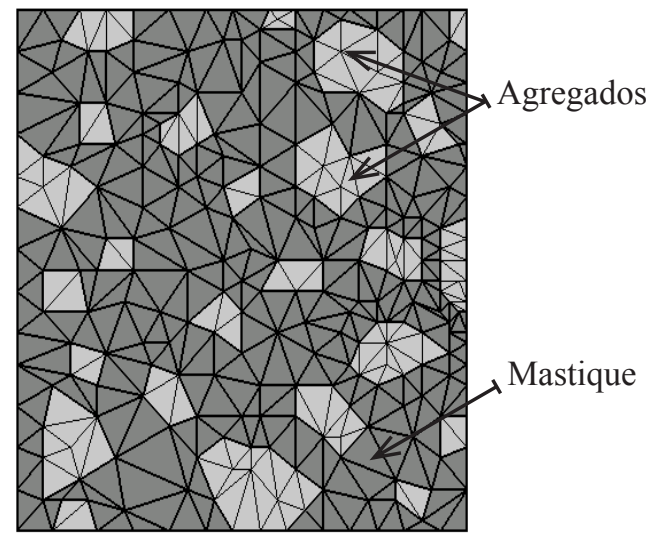

Figura 5: Malha de elementos finitos com elementos de interface para o EVR
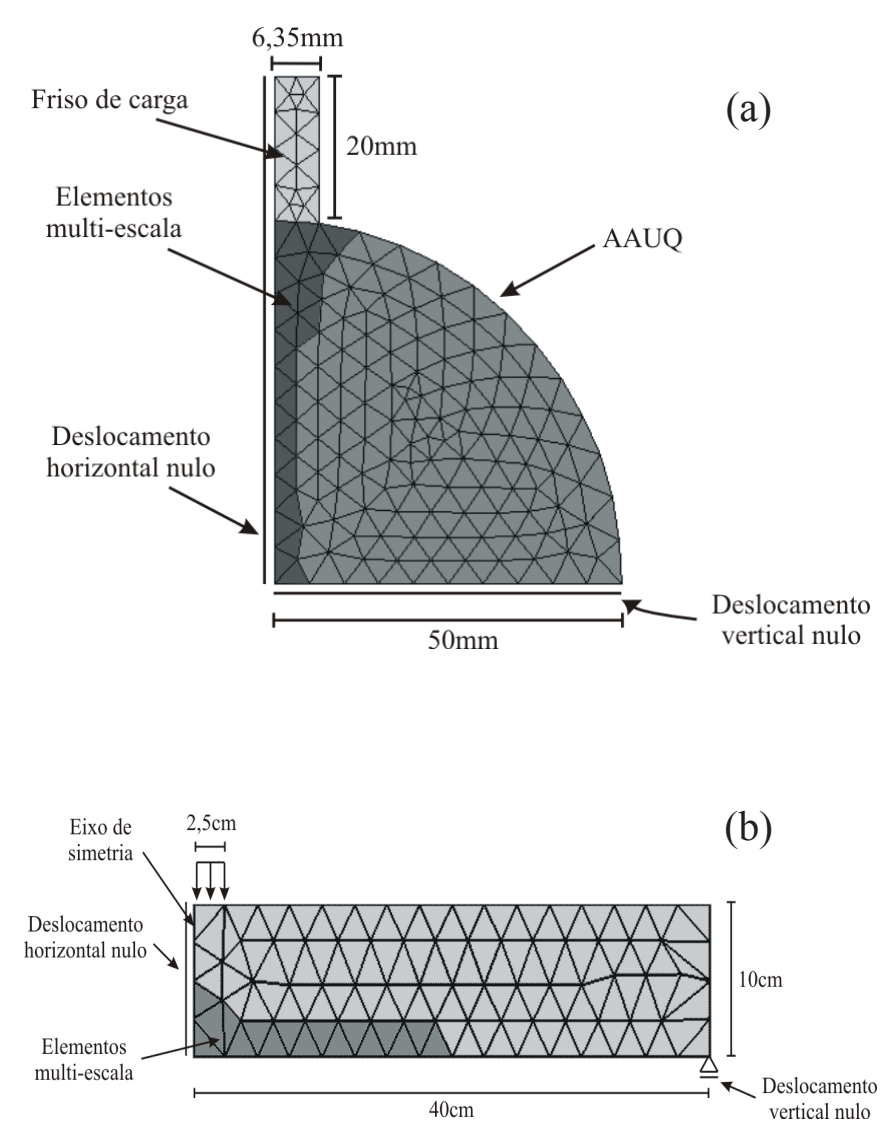

Figura 6: Malhas de elementos finitos nas simulações dos ensaios de (a) compressão diametral e (b) fadiga por flexão em viga

Vale ressaltar que foram inseridos elementos de interface ao longo de toda a malha da viga (exceto no contorno da viga) para ilustrar a evolução simultânea do dano tanto na escala local como na escala global. Além disso, é importante salientar que as simulações em viga são apenas ilustrativas, uma vez que não foram realizados ensaios experimentais em viga, sendo o objetivo destas simulações mostrar a capacidade do modelo em simular os fenômenos de acúmulo de deformação permanente e de trincamento por fadiga.

\section{SIMULAÇÃO DO ENSAIO DE COMPRESSÃO DIAMETRAL}

Como a espessura dos corpos de prova cilíndricos é pequena, considerou-se o estado plano de tensão nas simulações desse ensaio (Zhang et al., 1997). As taxas de deslocamento diametral usadas foram de $0,1 \mathrm{~mm} / \mathrm{s}$ e $0,4 \mathrm{~mm} / \mathrm{s}$. De modo a normalizar os resultados experimentais, a força atuante no friso foi dividida pela espessura dos corpos de prova. A Figura 7 mostra a evolução da força normalizada atuante no friso de carga com o tempo para ambas as taxas. Os resultados experimentais correspondem à média de três corpos de prova.

A partir da Figura 7, pode-se verificar que os resultados obtidos pelo modelo multi-escala estão coerentes com os resultados experimentais. As diferenças observadas podem ter sido provocadas por diversos fatores, dentre os quais se destacam: $i$ ) o uso de elementos finitos simples e de malhas pouco "discretizadas" (limitação de tempo computacional); ii) a hipótese de que $\ell_{\text {local }}<<\ell_{\text {global }} ;$ iii) as limitações experimentais; $i v$ ) a calibração (e não determinação experimental) dos parâmetros de dano; e v) a hipótese de estado plano de tensão.

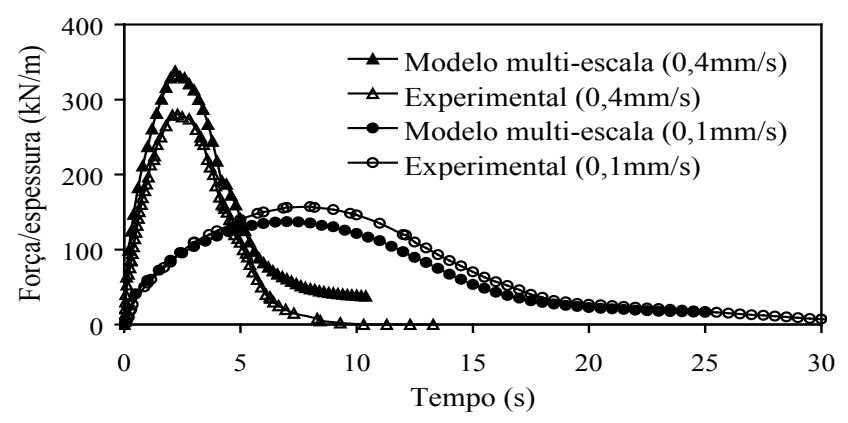

Figura 7: Resultados numéricos e experimentais para as taxas de 0,1 e $0,4 \mathrm{~mm} / \mathrm{s}$

A partir dos resultados, observou-se que as distribuições das tensões obtidas numericamente estão de acordo com os resultados mostrados no estudo de Zhang et al. (1997), o qual se baseia nas equações analíticas de Hondros (1959). Além disso, pôde-se observar que a região próxima ao friso de carga é a 
região mais solicitada em termos de magnitude das tensões; e que as tensões de compressão, verticais e horizontais, e as tensões de cisalhamento máximas (nas proximidades do friso de carga) são maiores em magnitude do que a tensão horizontal de tração máxima (no centro do corpo de prova).

Com o objetivo de se determinar, de forma qualitativa, a distribuição do dano (redução das tensões no corpo de prova) devido à dissipação de energia na escala local, simulou-se o ensaio de compressão diametral (taxa de $0,1 \mathrm{~mm} / \mathrm{s}$ ) considerando-se apenas a escala global (sem elementos multi-escala). Em seguida, calculou-se a diferença entre as tensões nos elementos para as duas situações no final da simulação, de modo a obter-se a distribuição da diferença de tensões, $\Delta \sigma_{i j}^{D}$, no corpo de prova, como mostra a Figura 8 ( $x$ - horizontal; $y$ - vertical). Note-se que, nessa figura, uma redução de tensões de tração produz um valor positivo, enquanto uma redução de tensões de compressão produz um valor negativo. A Figura 8 mostra ainda que as maiores diferenças de tensões, em magnitude, estão localizadas nas proximidades do friso de carga, o que era esperado, visto que tal região é a mais solicitada. Além disso, a redução de tensões compressivas é maior em magnitude que a redução de tensões de tração.

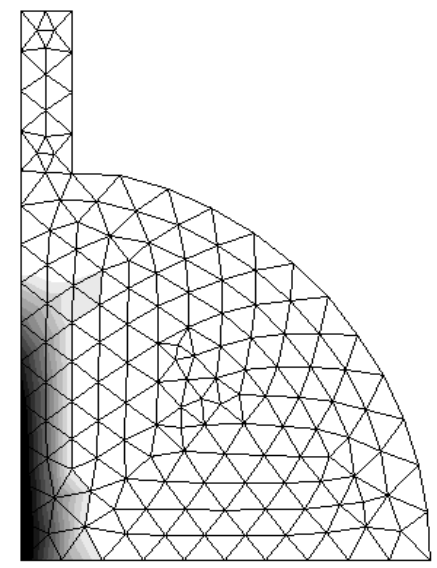

(a)

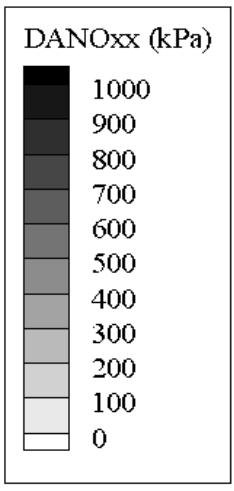

DANOyy $(\mathrm{kPa})$

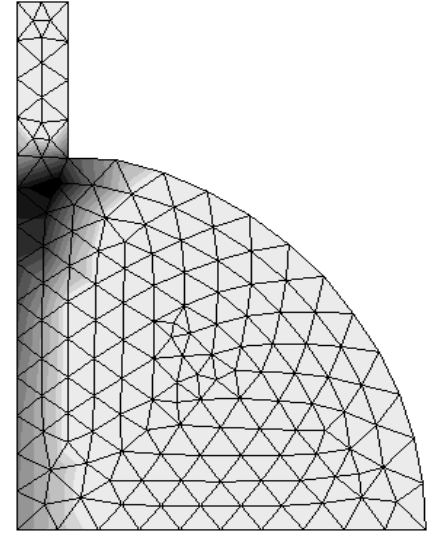

(c)
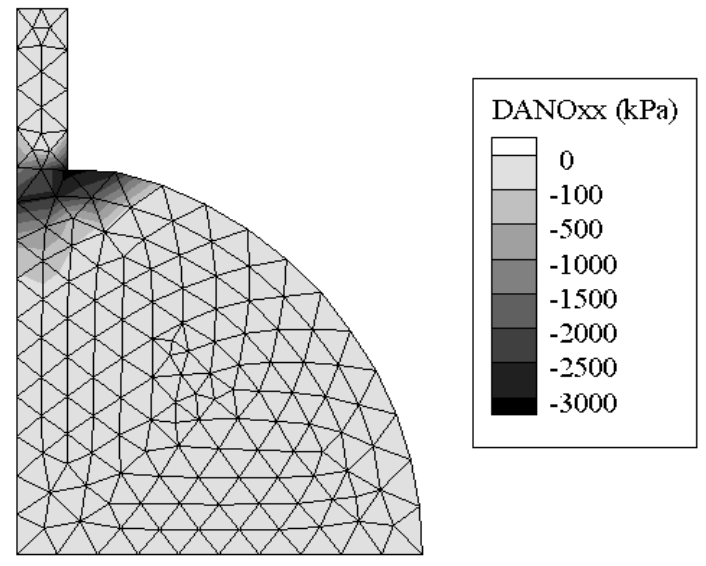

(b)

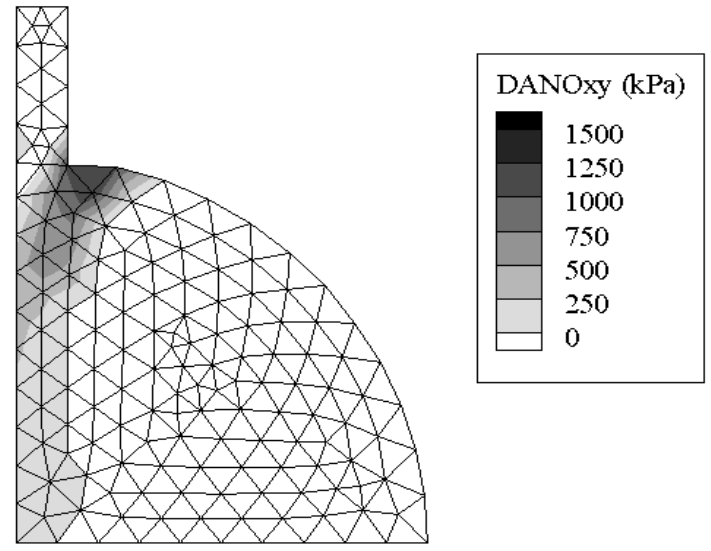

(d)

Figura 8: Distribuição da diferença de tensões (a) horizontais de tração; (b) horizontais de compressão;

(c) verticais e (d) de cisalhamento, para a taxa de $0,1 \mathrm{~mm} / \mathrm{s}$ 
Analisando-se agora o que ocorreu na escala local, pode-se verificar a evolução do dano na forma de micro-trincas nas diversas regiões do corpo de prova. Para tanto, foram escolhidos três elementos em regiões de solicitações distintas do corpo de prova, como mostra a Figura 9.

No caso do elemento $C$, não se observaram macro-trincas na escala local, mas este apresentou rigidez quase nula na direção horizontal devido à existência de inúmeras micro-trincas, especialmente no contorno dos agregados. As estruturas locais, para a taxa de $0,1 \mathrm{~mm} / \mathrm{s}$, nos elementos A e B (Figura 9) são mostradas nas Figuras 10 e 11, respectivamente. Os instantes de tempo escolhidos correspondem ao pico da tensão horizontal média no EVR e ao instante em que se obtém rigidez nula na escala local. Os deslocamentos horizontais mostrados foram magnificados em dez vezes para permitir uma melhor visualização.

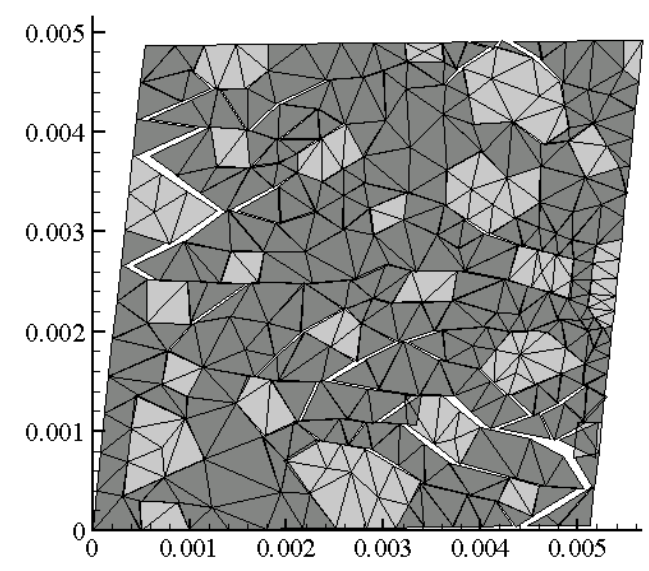

(a)

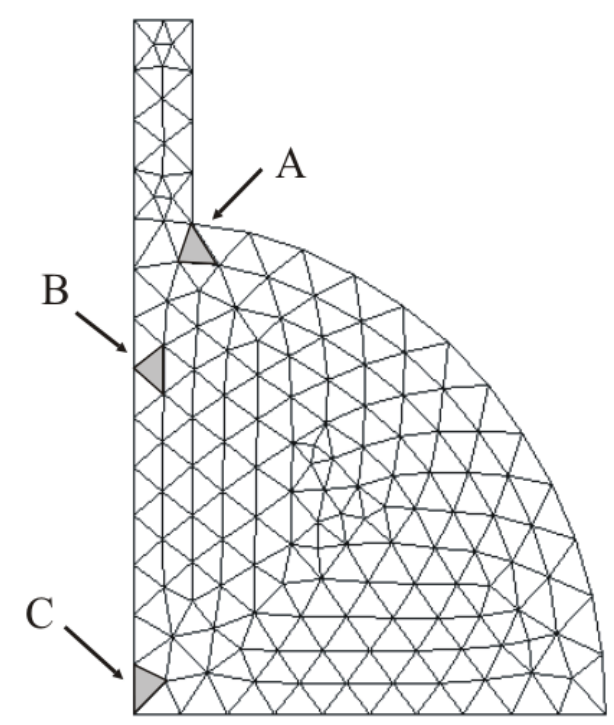

Figura 9: Elementos escolhidos em três regiões de solicitações distintas

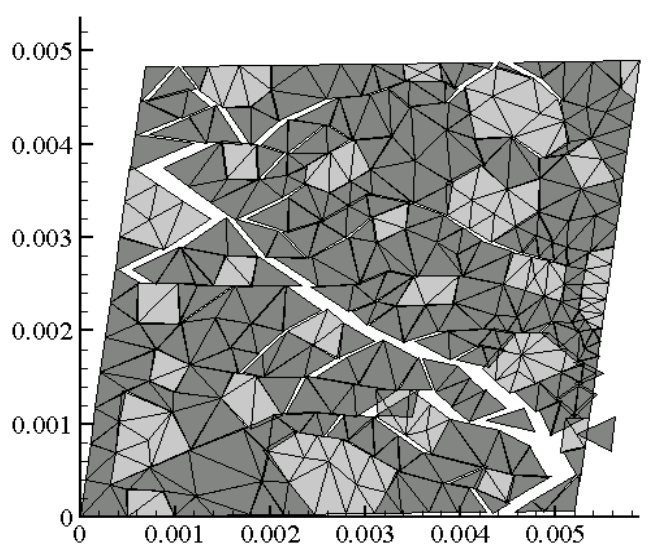

(b)

Figura 10: Estrutura local do elemento A para (a) $t=8,5 \mathrm{~s}$ e (b) $t=10 \mathrm{~s}$ para a taxa de $0,1 \mathrm{~mm} / \mathrm{s}$

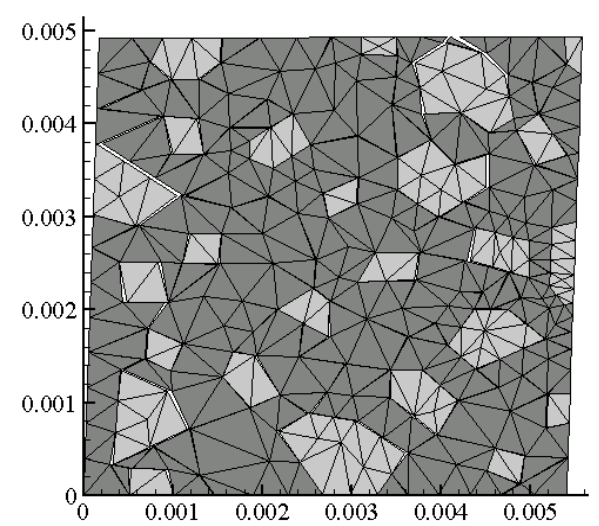

(a)

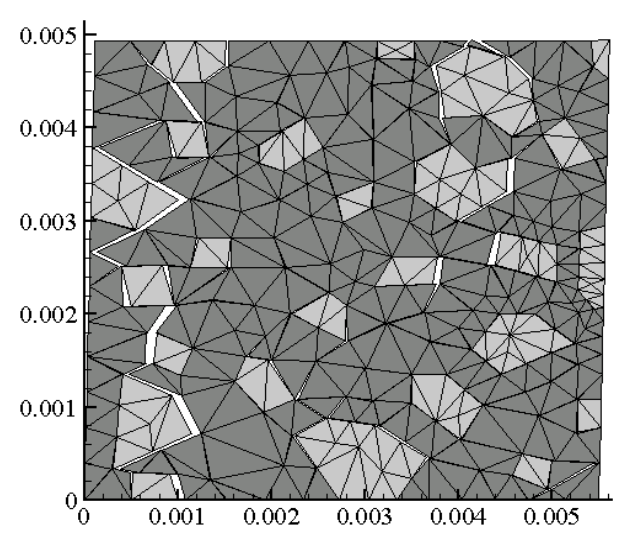

(b)

Figura 11: Estrutura local do elemento B para (a) $t=15 \mathrm{~s}$ e (b) $t=25 \mathrm{~s}$ para a taxa de $0,1 \mathrm{~mm} / \mathrm{s}$ 
As Figuras 10 e 11 mostram que a região próxima ao friso de carga é a região que primeiro apresentou trincas visíveis na escala local, provocadas principalmente pela combinação de tensões compressivas e de cisalhamento. De acordo com a simulação, com a redistribuição das tensões ao longo do corpo de prova provocada pela falência estrutural da região próxima ao friso de carga (Figura 10), o dano passa a se propagar mais intensamente nas regiões centrais do corpo de prova (Figura 11), onde atuam principalmente tensões verticais de compressão e horizontais de tração. As estruturas locais para a taxa de $0,4 \mathrm{~mm} / \mathrm{s}$ apresentaram configuração semelhante.

É importante ressaltar que, embora não se tenha observado, aparentemente, ruptura por compressão, as tensões de compressão, tanto horizontais como verticais, desempenham papel importante no processo de evolução do dano. Além disso, a perda de rigidez na direção vertical devido à propagação de micro-trincas por tração na direção horizontal e por cisalhamento produz perdas de tensão de compressão vertical, resultando, portanto, na queda da força de reação vertical do corpo de prova.

Vale salientar que os resultados numéricos aqui apresentados podem ser ainda melhorados caso todos os elementos globais sejam considerados multi-escala e caso os parâmetros de dano sejam determinados experimentalmente (Williams, 2001; Freitas et al., 2005), em vez de calibrados.

\section{SIMULAÇÃO DE CARREGAMENTO CÍCLICO DE FLEXÃO EM VIGA}

O objetivo das simulações em viga é ilustrar a capacidade do modelo multi-escala em simular os fenômenos de deformação permanente e de trincamento por fadiga, os quais constituem os principais tipos de falha observados nos pavimentos asfálticos. Para todas as simulações em viga, considerou-se o estado plano de tensão. O carregamento cíclico semi-senoidal (hipotético) constitui-se de dez ciclos com pico de $800 \mathrm{kPa}$ e período de $4 \mathrm{~s}$ seguidos de um intervalo de repouso de $30 \mathrm{~s}$ (Figura 12). O incremento de tempo usado nas simulações numéricas foi de $0,5 \mathrm{~s}$.

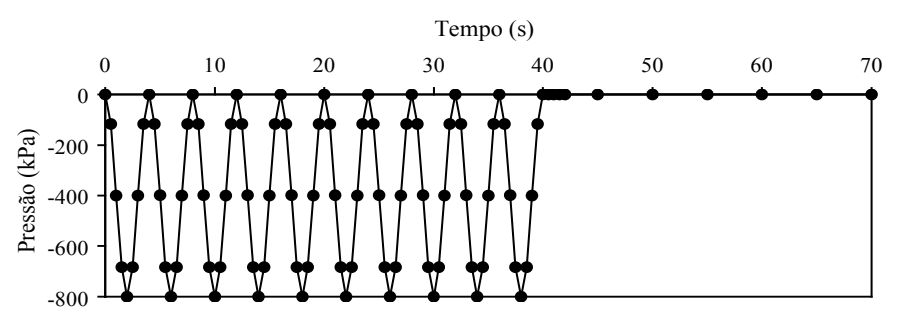

Figura 12: Carregamento usado nas simulações em viga
Basicamente, duas situações distintas foram consideradas. Na primeira (situação 1) não se considerou a evolução do dano para ambas as escalas global e local, mas todos os elementos T3 que constituem a viga foram considerados multi-escala. $\mathrm{O}$ intuito é modelar a deformação permanente produzida pelo comportamento viscoelástico do mastique.

$\mathrm{Na}$ segunda análise (situação 2), considerou-se a evolução do dano na forma de trincas em ambas as escalas através de elementos de interface dispostos ao longo das malhas de elementos finitos. Neste caso, apenas os elementos mais solicitados foram considerados multi-escala, conforme mostra a Figura 6b. Dentre os elementos multi-escala mostrados na Figura 6b, escolheram-se três elementos em regiões distintamente solicitadas para analisarse suas respectivas estruturas locais (Figura 13).

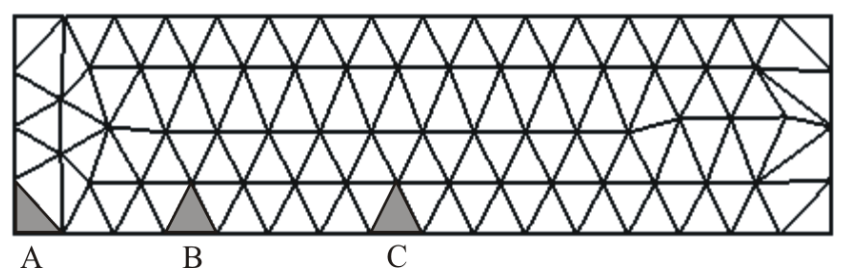

Figura 13: Elementos multi-escala escolhidos para a análise da estrutura local

A Figura 14 apresenta o histórico da deflexão máxima observada abaixo do carregamento no centro da viga para os casos analisados. A Figura 14 mostra ainda os resultados para o caso de um mastique hipotético menos consistente, com módulo de relaxação duas vezes menor que o mastique original, ou seja, sendo os coeficientes $E_{\mathrm{i}}$ 's da série de Prony do mastique original divididos por dois $\left(E_{i} / 2\right)$. Os resultados obtidos para este mastique hipotético serão discutidos mais adiante.

Note-se que a Figura 14 também mostra a deflexão máxima para o caso onde nenhum elemento é considerado multi-escala, sendo o comportamento constitutivo destes regido pelo módulo de relaxação determinado numericamente para a AAUQ. Observe que os resultados deste caso se mostraram em concordância com os resultados obtidos para a situação 1 .

Note-se ainda que, devido ao comportamento viscoelástico do mastique e, conseqüentemente, da AAUQ, existe uma defasagem no tempo das deflexões com relação ao carregamento aplicado. No caso desta simulação, os picos da deflexão máxima ocorreram $0,5 \mathrm{~s}$ após os picos do carregamento aplicado. 


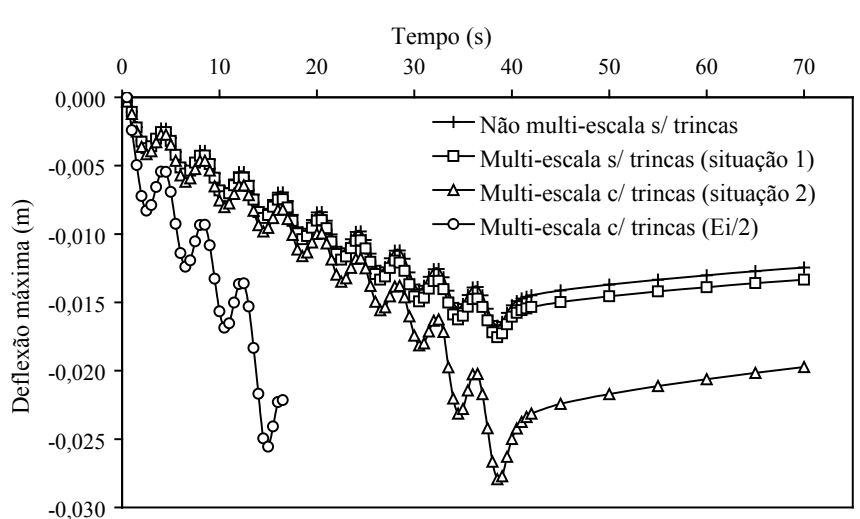

Figura 14: Histórico da deflexão máxima no centro da viga

A partir da análise multi-escala sem a consideração da propagação de trincas, pode-se perceber o acúmulo de deformações permanentes provocado pelo comportamento viscoelástico do mastique. Embora se acumulem deformações permanentes, a amplitude da deflexão se mantém constante para todos os ciclos.

Para o caso com trincas em ambas as escalas, observam-se deflexões maiores, conforme a Figura 14, provocadas inicialmente pela redução da rigidez na escala local (microtrincas) e, posteriormente, pela redução da rigidez na escala global (macrotrincas). Note-se, a partir da Figura 14, que há um aumento brusco na amplitude das deflexões no nono ciclo, o qual é produzido pela propagação de uma trinca na escala global, conforme mostra a Figura 15.

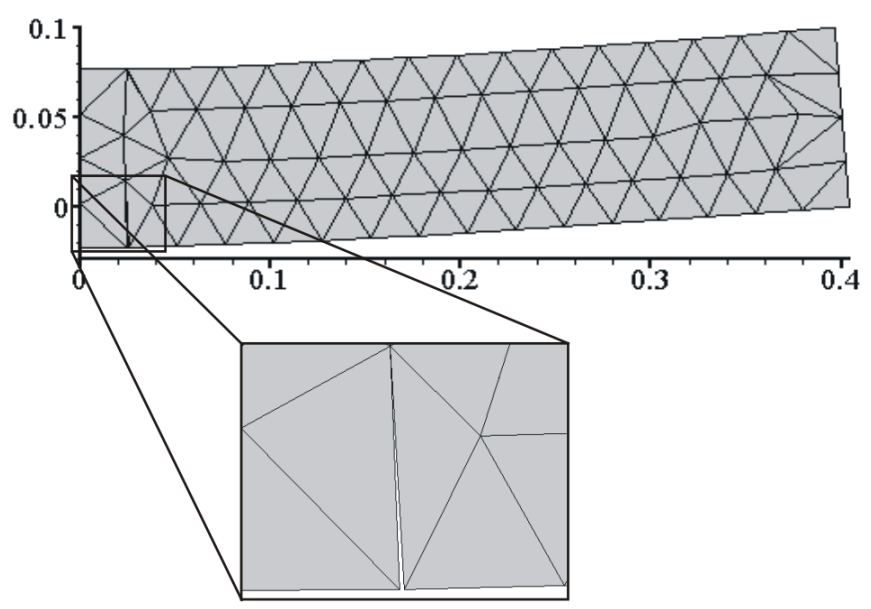

Figura 15: Configuração da viga para o caso multi-escala com trincas em ambas as escalas em $t=34,5 \mathrm{~s}$
A propagação de trincas na escala local, embora não produza um aumento brusco na deflexão global, produz uma redução na rigidez do material na escala global, o que provoca um aumento gradativo na deflexão da escala global (Figura 14). Além disso, essa redução de rigidez produz uma queda também gradativa na tensão horizontal máxima resistida pelo material na escala global, como mostra a Figura 16.

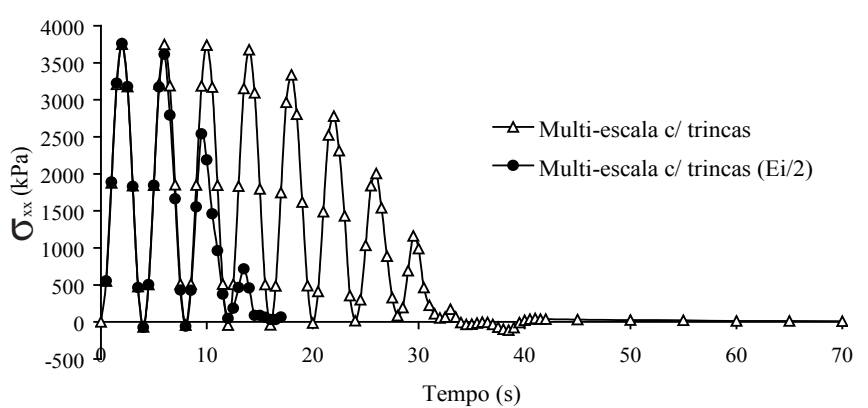

Figura 16: Histórico da tensão horizontal observada no elemento global A

A partir das Figuras 14 e 16, as quais mostram o acúmulo de deformações permanentes e a perda da resistência do material, respectivamente, ao longo dos ciclos de carga, pode-se verificar a capacidade do modelo em simular os fenômenos de trincamento por fadiga e de acúmulo de deformação permanente (tanto devido ao comportamento viscoelástico do mastique como devido à formação e propagação de microtrincas).

As Figuras 17, 18 e 19 apresentam as estruturas locais (para a situação 2) em tempos distintos para os elementos A, B e C da Figura 13, respectivamente. Os tempos escolhidos correspondem ao pico de deflexão do sexto ciclo e ao final da simulação. Os deslocamentos horizontais foram ampliados em dez vezes para permitir uma melhor visualização.

A partir das Figuras 17, 18 e 19, pode-se perceber que a estrutura local da região mais solicitada (Figura 17) se apresentou mais danificada que as demais, o que era esperado. Note-se que é justamente para este tipo de problema, onde há um gradiente de deformações ao longo da estrutura, que os modelos multi-escala se mostram mais atraentes, especialmente quando a evolução do dano depende do histórico do carregamento. 


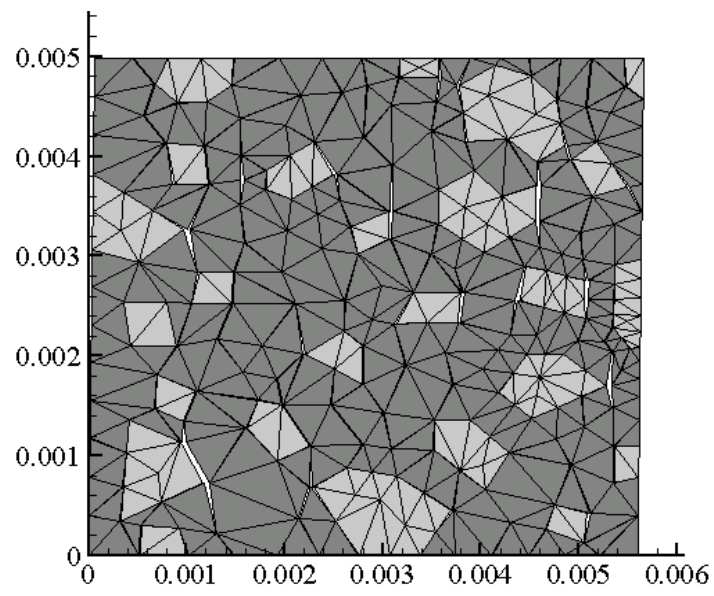

(a)

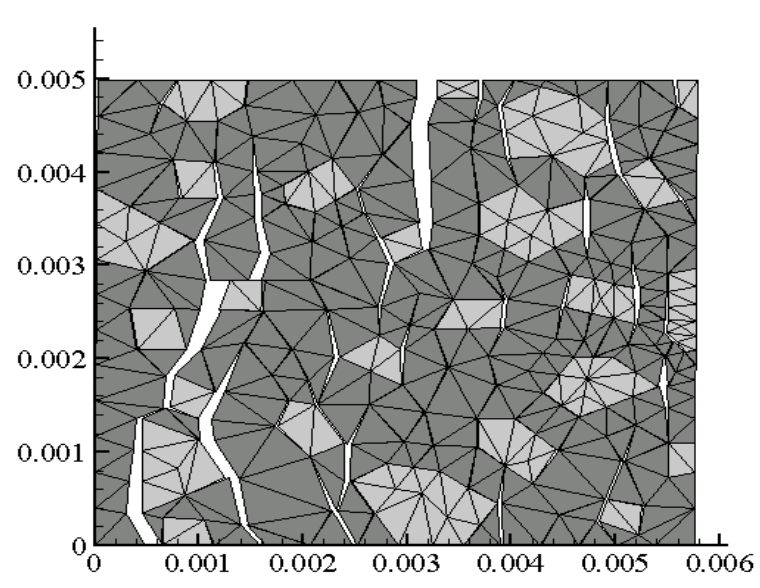

(b)

Figura 17: Estrutura local do elemento A para (a) $t=22,5 \mathrm{~s} \mathrm{e} \mathrm{(b)} t=70 \mathrm{~s}$

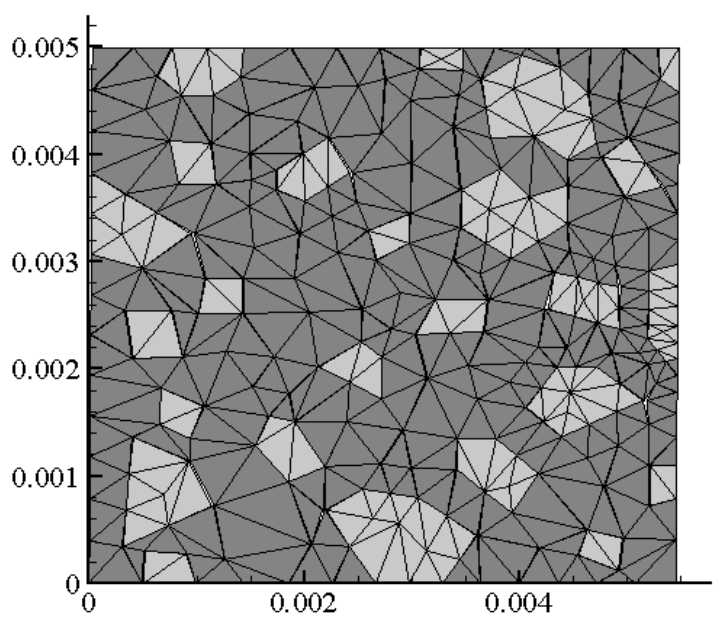

(a)

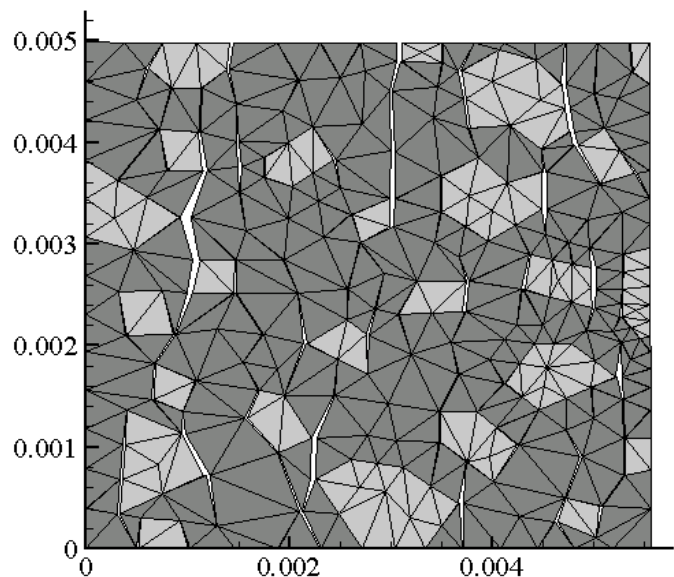

(b)

Figura 18: Estrutura local do elemento B para (a) $t=22,5 \mathrm{~s}$ e (b) $t=70 \mathrm{~s}$

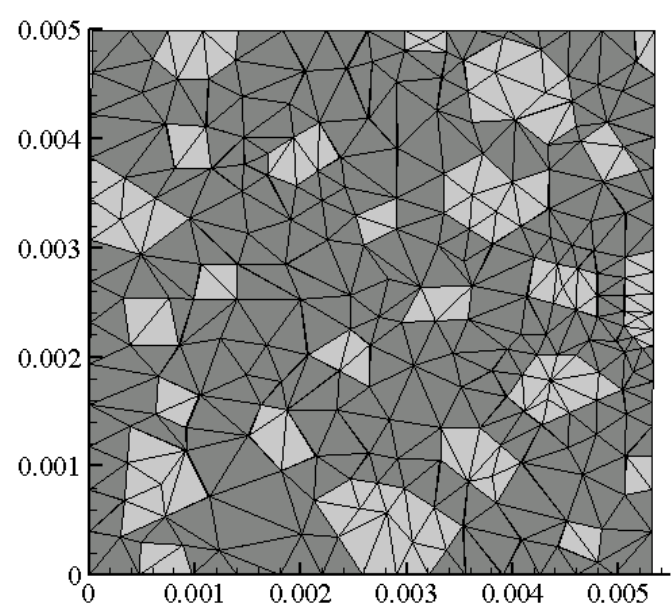

(a)

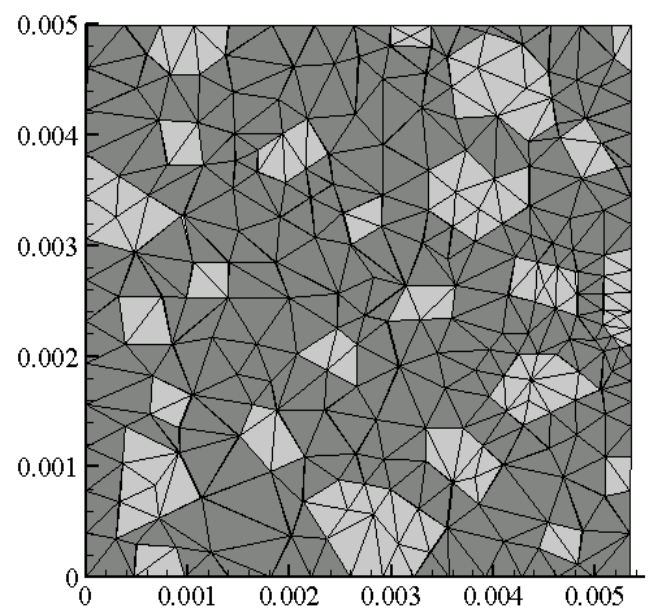

(b)

Figura 19: Estrutura local do elemento C para (a) $t=22,5 \mathrm{~s}$ e (b) $t=70 \mathrm{~s}$ 
Para ilustrar a capacidade do modelo multi-escala em avaliar o desempenho de misturas asfálticas para diferentes constituintes, considerou-se hipoteticamente um novo EVR constituído pela mesma fração de agregados, porém com um mastique com módulo de relaxação duas vezes menor. Para tanto, dividiram-se todos os coeficientes $E_{\mathrm{i}}$ 's da série de Prony do mastique original por dois e recalculouse o módulo de relaxação da AAUQ para este novo mastique usando o mesmo procedimento descrito em Souza (2005). Neste caso, o novo mastique apresenta uma fluência maior e corresponderia, por exemplo, a um mastique fabricado com um CAP menos consistente.

As Figuras 14 e 16 apresentam os resultados para este novo mastique. Observa-se da Figura 14 que, neste caso, a viga deforma mais rapidamente, como esperado, de modo que o dano também evolui mais rapidamente (Allen e Searcy, 2001), fazendo com que a falência estrutural da viga ocorra nos primeiros ciclos (quarto ciclo de carga), conforme Figura 16. É importante ressaltar a versatilidade do modelo computacional multi-escala na avaliação do desempenho dos dois mastiques diferentes, bastando, para tanto, recalcular o módulo de relaxação da nova AAUQ, modificar as propriedades do novo mastique e da nova AAUQ no arquivo de entrada e executar o programa novamente.

\section{CONCLUSÕES}

O presente trabalho tratou do modelo computacional multi-escala apresentado por Souza (2005) para análise estrutural de compósitos viscoelásticos, o qual foi aplicado à modelagem de misturas asfálticas do tipo AAUQ. O programa multi-escala desenvolvido se baseia no Método dos Elementos Finitos, o que o torna bastante versátil e de fácil aplicação na solução de problemas com diversas geometrias. O programa realiza a análise em apenas duas escalas (global e local).

Vale ressaltar que, além da heterogeneidade do material, as análises locais podem considerar a formação e propagação de trincas ao longo do mastique e nas interfaces mastique-agregados. Assim sendo, o modelo é capaz de considerar a anisotropia na microestrutura produzida pela distribuição interna e orientação dos agregados e das trincas formadas. A formação e propagação de trincas foram modeladas através de um modelo de zona coesiva viscoelástico.

Uma das principais vantagens dos modelos multi-escala é a visualização, por parte do analista, das interações entre os constituintes do compósito, o que permite um melhor entendimento do comportamento do material e dos fenômenos de deterioração que ocorrem nas escalas menores e que determinam o comportamento da estrutura na escala maior. A partir deste entendimento mais esclarecido, pode-se, então, projetar materiais mais adequados para cada tipo de aplicação estrutural de modo a possibilitar maior segurança, confiabilidade e economia aos projetos estruturais e permitir um melhor aproveitamento dos materiais.

No caso das misturas asfálticas, por exemplo, é possível se desenvolver um método de projeto de misturas baseado em análises micromecânicas, o qual possa tirar o máximo proveito dos agregados e ligantes asfálticos disponíveis em cada região. Do mesmo modo, pavimentos asfálticos duráveis podem ser dimensionados levando-se em conta as peculiaridades dos materiais disponíveis.

Além disso, por se basearem nas propriedades fundamentais dos materiais constituintes individuais, os modelos multi-escala permitem que várias combinações de constituintes diferentes e de suas respectivas frações volumétricas sejam testadas computacionalmente sem a necessidade de realização de grande quantidade de ensaios laboratoriais.

\section{Agradecimentos}

À equipe do Laboratório de Mecânica dos Pavimentos, LMP/ DET/UFC. Os autores agradecem à Agência Nacional do Petróleo e ao CNPq pelas suas respectivas bolsas.

\section{REFERÊNCIAS}

Allen, D. H. (2001) Homogenization Principles and their Application to Continuum Damage Mechanics. Composites Science and Technology, v. 61, p. 2223-2230.

Allen, D. H. e C. R. Searcy (2001) A Micromechanical Model for a Viscoelastic Cohesive Zone. International Journal of Fracture, v. 107, p. 159-176.

Allen, D. H. e C. Yoon (1998) Homogenization Techniques for Thermoviscoelastic Solids Containing Cracks. International Journal of Solids and Structures, v. 35, p. 4035-4054.

Bazant, Z. P. e J. Planas (1998) Fracture and Size Effect in Concrete and Other Quasibrittle Materials. CRC Press, EUA.

Caiazzo, A. A. e F. Costanzo (2000) On the Constitutive Relations of Materials with Evolving Microstructure due to Microcracking. International Journal of Solids and Structures, v. 37 , p. $3375-3398$.

Caiazzo, A. A. e F. Costanzo (2001) Modeling the Constitutive Behavior of Layered Composites with Evolving Cracks. International Journal of Solids and Structures, v. 38, p. 34693485 .

Cuthill, E. e J. Mckee (1969) Reducing the bandwidth of sparse symmetric matrices. Proceedings of the 24th National Conference of the ACM. 
Daniel, J. S. e Y. R. Kim (2002) Development of a Simplified Fatigue Test and Analysis Procedure using a Viscoelastic, Continuum Damage Model. Journal of the Association of Asphalt Paving Technologists, AAPT.

DNER (1995) DNER ME 043/95: Método de Ensaio Misturas Betuminosas a Quente. Ensaio Marshall para Misturas Betuminosas. Departamento Nacional de Estradas de Rodagem. Ministério dos Transportes, Brasil.

Feyel, F. e J-L. Chaboche (2000) FE2 Multiscale Approach for Modelling the Elastoviscoplastic Behavior of Long Fibre $\mathrm{SiC} / \mathrm{Ti}$ Composite Materials. Computer Methods in Applied Mechanics and Engineering, v. 183, p. 309-330.

Freitas, F.A. C. (2002) Modelagem da Formação e Propagação de Trincas em Misturas Betuminosas Através do Método dos Elementos Finitos. Dissertação de Mestrado. Universidade Federal do Ceará, Fortaleza.

Freitas, F.A. C.; Soares, J.B. eAllen, D.H. (2005) Determinação Experimental de Parâmetros de Dano Viscoelásticos em Misturas Asfálticas. Anais do Congresso de Pesquisa e Ensino em Transportes, ANPET.

Goodrich, J. L. (1991) Asphaltic Binder Rheology, Asphalt Concrete Rheology and Asphalt Concrete Mix Propreties. Journal of the Association of Asphalt Paving Technologists, AAPT, v. 60, p. 80-120.

Haj-Ali, R. M.eA. H. Muliana (2004)AMulti-scale Constitutive Formulation for the Nonlinear Viscoelastic Analysis of Laminated Composite Materials and Structures. International Journal of Solids and Structures, v. 41, p. 3461-3490.

Hondros, G. (1959) The Evaluation of Poisson's Ratio and the Modulus of Materials of a Low Tensile Resistance by the Brazilian (Indirect Tensile) Test with Particular Reference to Concrete. Australian Journal of Applied Sciences, v. 10, n. 3, p. 243-268.

Kouznetsova, V. G. (2002) Computational homogenization for the multi-scale analysis of multi-phase materials. Ph.D. Dissertation, TU-Eindhoven, Eindhoven, Holanda.

LCPC (1997) French Design Manual for Pavement StructureGuide Technique. Laboratoire Central des Ponts et Chaussées et Services d'Études Techniques des Routes et Eutoroutes, $\mathrm{n}^{\circ}$ 502 707, França.

Mehta, P. K. e P. J. M. Monteiro (1993) Concrete, Structure, Properties and Materials. Prentice Hall, New Jersey, EUA.

Motta, L. M. G.; I. Tonial; L. M. Leite e R. S. Constantino (1996) Curso sobre Programa SHRP: Aplicação a Ligantes, Agregados e Misturas Betuminosas, IBP, Rio de Janeiro.

Park, S. W. e R. A. Schapery (1999) Methods of Interconversion between Linear Viscoelastic Material Functions. Part I - A Numerical Method Based on Prony Series. International Journal of Solids and Structures, v. 36, p. 1653-1675.

Pinto, S. (1991) Estudo do Comportamento à Fadiga de Misturas Betuminosas e Aplicação na Avaliação Estrutural de Pavimentos. Tese de Doutorado, COPPE/UFRJ, Rio de Janeiro, RJ.

Searcy, C. R. (2004) A Multi-scale model for Predicting Damage Evolution in Heterogeneous Viscoelastic Media. Ph.D. Dissertation, Texas A\&M University, College Station, EUA.
Seidel, G. D.; D. H. Allen; K. L. E. Helms e S. E. Groves (2004) A Model for Predicting the Evolution of Damage in Viscoelastic Particle-Reinforced Composites. A ser publicado em Mechanics of Materials.

SHRP (1994a) Permanent Deformation Response of Asphalt Aggregate Mixes. Strategic Highway Research Program A-415, National Research Council, Estados Unidos.

SHRP (1994b) Superior Performing Asphalt Pavements (Superpave): The Products of the SHRP Asphalt Research Program. Strategic Highway Research Program A-410. National Research Council, Estados Unidos.

SHRP (1994c) The Superpave Mix Design System Manual of Specification, Test Methods, and Practices. Strategic Highway Research Program A-379, National Research Council, Estados Unidos.

Souza, F. V. (2005) Modelo Multi-Escala para Análise Estrutural de Compósitos Viscoelásticos Suscetiveis ao Dano. Dissertação de Mestrado. Universidade Federal do Ceará, Fortaleza.

Souza, F. V. e J. B. Soares (2003a) Previsão do Comportamento Mecânico de Misturas Asfálticas a partir dos Resultados do Ensaio de Creep Estático. In: CNT/ANPET (org.) / LGE (ed.) Transporte em Transformação VII - Trabalhos Vencedores do Prêmio CNT Produção Acadêmica 2002, Brasília, Brasil.

Souza, F. V. e J. B. Soares (2003b) Efeito da Consideração do Comportamento Viscoelástico Linear do Revestimento no Cálculo de Tensões e Deslocamentos em Pavimentos Asfálticos. Anais do Congresso de Pesquisa e Ensino em Transportes, ANPET.

Souza, F. V.; J. B. Soares; D. H. Allen e F. Evangelista Jr. (2005) Model for Predicting Damage Evolution in Heterogeneous Viscoelastic Asphaltic Mixtures. Transportation Research Record, Transportation Research Board, National Research Council, EUA.

Stroeven, M.; H. Askes e L. J. Sluys (2004) Numerical Determination of Representative Volumes for Granular Materials. Computer Methods in Applied Mechanics and Engineering, v. 193, p. 3221-3238.

Tecgraf5 (1997) Mtool: Bidimensional Mesh Tool, versão 3.0. Grupo de Tecnologia em Computação Gráfica, PUC-Rio.

Williams, J. J. (2001) Two Experiments for Measuring Specific Viscoelastic Cohesive Zone Parameters. Master's Thesis, Texas A\&M University, College Station, EUA.

Yi, Y-M.; S-H. Park e S-K. Youn (1998) Asymptotic Homogenization of Viscoelastic Composites with Periodic Microstructures. International Journal of Solids and Structures, v. 35 , n. 17 , p. 2039-2055.

Zhang, W.; A. Drescher e D. E. Newcomb (1997) Viscoelastic Analysis of Diametral Compression of Asphalt Concrete. Journal of Engineering Mechanics, v. 123, n. 6, p. 596-603.

Flávio Vasconcelos de Souza (flaviovs@gmail.com) Jorge Barbosa Soares (jsoares@det.ufc.br)

Artigo recebido em 17/10/2004 e aprovado em 28/07/2005. 